\title{
PERANCANGAN BUKU PEDOMAN UMUM EJAAN BAHASA INDONESIA SEBAGAI MEDIA PEMBELAJARAN EJAAN DI SEKOLAH
}

\author{
Puji Anto', M. Sjafei Andrijanto², Taufiq Akbar ${ }^{3}$ \\ Program Studi Desain Komunikasi Visual \\ Fakultas Bahasa dan SeniUniversitas Indraprasta PGRI \\ pujianto@unindra.ac.id1, grapickology.ta@gmail.com2,ad3_sj410@yahoo.com3
}

\begin{abstract}
Abstrak
Tujuan perancangan buku Pedoman Umum Ejaan Bahasa Indonesia (PUEBI) adalah sebagai media pembelajaran ejaan sehingga siswa mampu menguasai penggunaannya sejak dini dengan benar. Tingkat penguasaan ejaan yang benar, siswa akan mampu membuat karya tulis yang berkualitas. Pada tingkat pendidikan selanjutnya yaitu perguruan tinggi, peserta didik sudah terbiasa dengan penggunaan tata bahasa yang baik. Oleh sebab itu, peserta didik akan mudah menyelesaikan pendidikan tinggi yang pada akhir perkuliahannya dituntut untuk membuat karya tulis, yaitu berupa tugas akhir maupun skripsi. Perancangan ini mencakup materi tentang pengenalan ejaan yang terbaru, pemakaian huruf, penulisan kata, pemakaian tanda baca, penulisan unsur serapan. Metode penelitian yang digunakan dalam penelitian ini adalah metode kualitatif. Pengumpulan data melalui studi literatur, observasi, dan wawancara yang berhubungan dengan ejaan Bahasa Indonesia, untuk melakukan analisa data pustaka dan data lapangan. Hasil yang dicapai dalam perancangan buku PUEBI, yaitu menggunakan Layout antara lain adalah Copy Heavy Layout, Type Specimen Layout, Jumble Layout, dan Rebus Layout. Bagian isi menggunakan font Calibri Light yang masuk dalam kategori Sans Serif, yang dikatakan sebagai huruf yang tidak memiliki kait. Ilustrasi gambar digantikan dengan pengolahan huruf, sedangkan gambar ilustrasi hanya digunakan sebagai penunjang visual saja.Penggunaan warna menggunakan warna-warna pastel untuk memberikan kesan nyaman ketika dipandang mata.
\end{abstract}

Kata Kunci: Buku, Ejaan, Media Pembelajaran

\begin{abstract}
General Guidelines book design objectives Indonesian Spelling (PUEBI) is as a medium of learning spelling so that students are able to master its use since early correctly. Correct spelling mastery level, students will be able to make high quality paper. At the level of further education ie college, students are familiar with the use of good grammar. Therefore, learners will easily complete higher education at the end of the lecture is required to make a report, which formed the final project or thesis. This design includes material about the recent introduction of spelling, use of letters, spelling, use of punctuation, writing element uptake. The method used in this study is a qualitative method. Collecting data via literature study, observation, and interviews related to Indonesian spelling. for analysis of the literature data and field data. The results achieved in the design of the book PUEBI, ie using the Layout include Heavy Copy Layout, Type Specimen Layout, Jumble Layout, and Layout Rebus. Section contents using font Calibri Light into the category Sans Serif is said to be a letter that does not have a latch. Illustration picture is replaced with the processing of the letter, while the illustrations are only used as supporting visual only. The use of color using pastel colors to give the impression of comfort when the eye.
\end{abstract}

Keywords: Book, Spelling, Learning Media 


\section{PENDAHULUAN}

Penggunaan bahasa yang benar atau sesuai dengan kaidah kebahasaan selalu terkait dengan ejaan. Ejaan merupakan keseluruhan aturan pelafalan lambang-lambang bunyi ujaran sehingga terbentuk bunyi bahasa yang berupa sebuah kata atau kalimat dan mengandung makna tertentu, baik lisan maupun tulis.

Ejaan bahasa Indonesia sudah mengalami beberapa perubahan. Sebelumnya pernah berlaku Ejaan Van Ophuijsen (1901) dan Ejaan Soewandi (1947). Pada tahun 1972 dikeluarkan Pedoman Umum Ejaan Bahasa Indonesia yang Disempurnakan dan edisi revisi pada tahun 1987 yang di dalamnya menguraikan kaidah ejaan yang terbaru, terinci, dan lengkap. Kaidah ejaan yang terkandung dalam EYD sudah sangat lengkap, tetapi pelaksanaannya belum optimal. Hingga akhirnya pada tahun 2015 Menteri Pendidikan dan Kebudayaan melengkapi lagi pedoman ejaan bahasa Indonesia yang tentunya dengan beberapa perubahan dan penambahan terkait kedinamisan bahasa, maka keluarlah Surat Keputusan Menteri Pendidikan dan Kebudayaan Nomor 50 Tahun 2015 tentang Pedoman Umum Ejaan Bahasa Indonesia.

Melihat dari sejarahnya ejaan terus berubah, maka bisa diambil sebuah simpulan bahwasannya dengan seringnya ejaan itu berubah berarti ada prioritas yang utama terhadap ejaan. Perubahan demi perubahan terhadap ejaan mempunyai target yang harus dicapai. Salah satu target capainnya adalah meningkatnya kualitas tata bahasa yang ada di Indonesia, khususnya bagi para pelajar dan mahasiswa.

Permasalahan yang timbul dari dulu hingga sekarang adalah perubahan terus terjadi, sosialisasi terus dilakukan, tetapi aktualisasi penggunaan ejaan tersebut tidak signifikan. Faktanya, banyak sekali penggunaan bahasa Indonesia yang salah, terutama penggunaan bahasa Indonesia ragam tulis.Kesalahan penggunaan ejaan khususnya ragam tulis masih banyak terjadi di bidang apa pun khususnya pada dunia pendidikan. Banyak sekali ditemukan karya tulis siswa atau mahasiswa terjadi kesalahan dalam penulisan ejaan yang standar. Penggunaan tanda baca dan penulisan kata menjadi masalah utama dalam ragam tulis yang standar.

Sering berubahnya pedoman ejaan seharusnya disertai sosialisasi yang tepat sasaran. Selama ini sosialisasi pedoman ejaan dilakukan melalui media buku yang standar dan presentasipresentasi dalam seminar yang bersifat formalitas saja, tidak mendalam dan cenderung kurang menarik.

Sosialisasi seharusnya mempertimbangkan minimal objek dan medianya. Objek sangat penting untuk menjadi prioritas utama yang harus dipertimbangkan dalam menentukan media yang akan dipakai dan bahasa yang akan dipakai, maka perlu adanya kajian yang berkaitan dengan media, metode, dan Objek. Terkait dengan objek, pelaku pendidikan merupakan objek yang tepat untuk menjadi langkah pertama menyosialisasikan sebuah aturan baru. Salah satu pertimbangannya adalah dunia pendidikan merupakan proses transformasi ilmu dan menjadi motor penggerak perubahan terkait dengan iptek.

$\begin{array}{rrr}\text { Media } & \text { sosialisasi ejaan yang } \\ \text { diprogramkan } & \text { oleh } & \text { Badan } \\ \text { Pengembangan } & \text { dan Pembinaan } & \text { Bahasa } \\ \text { Kementerian } & \text { Pendidikan } & \text { dan }\end{array}$

Kebudayaan Indonesia, salah satunya menggunakan buku PUEBI. Buku yang diterbitkan oleh badan bahasa tersebut bersifat universal. Buku tersebut berlaku untuk semua objek, bisa masyarakat 
umum, pelajar, dan mahasiswa. Penggunaan desain dan tulisan dalam buku tersebut tidak mencerminkan segmentasi mana yang menjadi target sosialisasi.

Berlandaskan uraian di atas, penulis akan melakukan perancangan sebuah buku dengan mempertimbangkan objek yang menjadi sasaran sosialisasi PUEBI. Pemilihan media buku dilandasi oleh diberlakukannya program literasi sekolah. Konsep yang ditawarkan adalah menggunakan desain dengan layout dan typografi yang kekinian dengan pertimbangan segmentasinya. Oleh sebab itu, objek akan mempunyai daya tarik untuk mempelajari ejaan.

Rumusan masalah pada perancangan ini adalah bagaimana perancangan buku Pedoman Umum Ejaan Bahasa Indonesia sebagai media pembelajaran ejaan di sekolah. Perancangan buku ini mengambil momen terbitnya pedoman ejaan yang terbaru. Penggunaan media sosialisasi yang tepat sesuai sasaran, maka efektivitas capaian akan semakin tinggi. Objek perancangan buku ini adalah peserta didik sekolah menengah pertama dan peserta didik sekolah menengah atas. Penentuan objek ini dilandasi dengan intensitas penggunaan bahasa ragam tulis pada tingkat pendidikan tersebut. Pada tigkat pendidikan tersebut siswa melakukan kegiatan belajar-mengajar lebih banyak menggunakan ragam tulis.

Tujuan perancangan buku PUEBI ini adalah siswa mampu menguasai penggunaan ejaan sejak dini dengan benar. Melalui penguasaan ejaan yang benar, siswa mampu membuat karya tulis yang berkualitas. Pada tingkat pendidikan selanjutnya yaitu perguruan tinggi, peserta didik sudah terbiasa dengan penggunaan tata bahasa yang baik. Oleh sebab itu, peserta didik akan mudah menyelesaikan pendidikan tinggi yang pada akhir perkuliahaannya peserta didik dituntut untuk membuat karya tulis, yaitu berbentuk tugas akhir maupun skripsi.

Penulis berharap dengan perancangan buku ini mampu membantu pemerintah, khususnya guru dan dosen dalam proses pembelajaran tentang ejaan yang ada kaitannya dengan mata pelajaran bahasa Indonesia pada tingkat sekolah menengah, mata kuliah bahasa Indonesia, menulis kreatif, dan penulisan tugas akhir/skripsi pada tingkat perguruan tinggi.

\section{PEMBAHASAN}

Ejaan adalah keseluruhan peraturan melambangkan bunyi ujaran dan hubungan antara lambang-lambang itu (pemisahan dan penggabungannya dalam suatu bahasa). Secara teknis, ejaan ialah penulisan huruf, penulisan kata, dan pemakaian tanda baca (Arifin, 2008: 164).

Menurut Suyanto (2011: 90) ejaan adalah ilmu yang mempelajari tentang ucapan atau apa yang dilisankan oleh seseorang ditulis dengan perantara lambang-lambang atau gambar-gambar bunyi.

Menurut alwi dkk. (2014: 16) ejaan merupakan tata cara menulis bahasa indonesia dengan huruf latin.

Pedoman Umum Ejaan Bahasa Indonesia (PUEBI) adalah ejaan bahasa Indonesia yang berlaku sejak tahun 2015 . Ejaan ini menggantikan ejaan sebelumnya, yairu Ejaan Yang Disempurnakan (EYD)edisi revisi tahun 1987.

Berdasarkan pendapat para ahli di atas dapat disimpulkan bahwa ejaan adalah segala bentuk aturan terkait penulisan tata bahasa dalam bahasa Indonesia.

Buku juga merupakan bentuk pengabadian sebuah karya, bisa berupa karya sastra, peraturan-peraturan, undang-undang, dan lain sebagainya. 
Menurut KBBI Daring (2016), buku adalah lembar kertas yang berjilid berisi tulisan atau kosong; kitab. Hal yang sama juga disebutkan bahwa buku pedoman adalah buku yang digunakan sebagai acuan dalam melakukan sesuatu; buku acuan.

Menurut Suprana (dalamTriguno, 2013), buku adalah suatu bentuk benda karya manusia yang berfungsi sebagai salah satu media komunikasi atau informasi. Buku saat ini masih menjadi prioritas utama untuk mencari informasi ditengah perkembangan teknologi yang semakin pesat.

Berdasarkan pendapat para pakar di atas bisa diambil sebuah simpulan, bahwa buku masih menjadi prioritas utama dalam rangka mengabadikan karya seseorang maupun lembaga untuk menjadi acuan.

Proses perancangan sebuah buku pedoman harus mempertimbangkan beberapa hal, di antaranya:

1. Warna

Warna adalah sebuah spektrum tertentu terdapat di dalam cahaya yang sempurna/putih.

2. Garis

Garis menciptakan arah, gerak, dan energi. Garis tegas umumnya digunakan untuk menggambarkan fenomena alam, sedangkan garis lembut dapat menciptakan kesan feminim, melankolis ataupun kelunakan.

3. Ilustrasi

Ilustrasi secara umum berarti sebagai gambar yang menjelaskan atau menerangkan sesuatu yang berguna untuk merangsang daya tarik pembaca.

4. Tipografi

Tipografi berperan sebagai penyampai pesan komunikasi. Huruf mempunyai dampak pada ruang dalam layout. Oleh karen itu, tipografi harus mampu berkomunikasi dalam bentuk yang paling jelas dan terbaca.

5. Layout

Layout adalah tata letak dari suatu elemen desain yang ditempatkan dalam sebuah bidang yang tujuannya mengatur desain supaya menjadi indah dan menarik. Layout sangat berperan penting dalam perancangan buku pedoman ejaan bahasa Indonesia. Pada perancangan ini menggunakan layout yang menarik disesuaikan dengan segmentasinya, yaitu peserta didik.

Menurut Depdiknas (dalam Muhson, 2010), kata media berasal dari bahasa latin dan merupakan bentuk jamak dari kata medium yang secara harfiah berarti perantara atau pengantar. Makna umumnya adalah segala sesuatu yang dapat menyalurkan informasi dari sumber informasi kepada penerima informasi. Syukur (dalam Handayaningrum, 2010: 7) mengemukakan bahwa media pendidikan merupakan alat sebagai perantara untuk memudahkan proses belajar-mengajar, dalam rangka efektivitas komunikasi guru dan murid. Sedangkan Gagne dan Briggs (dalam Handayaningrum, 2010: 7) berpendapat bahwa media pembelajaran meliputi alat yang secara fisik dipakai untuk menyampaikan isi materi, yang terdiri dari buku, tape recorder, kaset, video kamera, video recorder, film, slide (gambar bingkai), foto, gambar, grafik, televisi, dan komputer.

Penggunaan media dalam proses pembelajaran memerlukan perencanaan yang terukur. Pengelompokan berbagai jenis media apabila dilihat dari segi perkembangan teknologi oleh Seels dan Glasgow (dalam Ali, 2009), dibagi ke dalam dua katagori luas, yaitu pilihan media tradisional dan media teknologi mutakhir. Media tradisional adalah ..."Cetak: Buku teks, Modul, teks 
terprogram, workbook, Majalah ilmiah, lembaran lepas (handout)"....

Pembelajaran adalah suatu kombinasi yang tersusun meliputi unsurunsur manusiawi, material, perlengkapan dan prosedur yang saling mempengaruhi mencapai tujuan pembelajaran (Oemar Hamalik, 2008:57).

Sesuai dengan pernyataan tersebut dapat dijelaskan bahwa pembelajaran merupakan sebuah usaha nyata yang dilakukan pendidik untuk menggerakkan peserta didik sehingga peserta didik mampu menyerap pengetahuan dan kegiatan yang di lakukan. Pembelajaran harus dikondisikan oleh seseorang yang dianggap ahli dalam kegiatan belajarmengajar.

Perancangan ini mencakup materi tentang pengenalan ejaan yang terbaru, pemakaian huruf, penulisan kata, pemakaian tanda baca, penulisan unsur serapan. Metode penelitian yang digunakan dalam penelitian ini adalah metode kualitatif. Pengumpulan data melalui studi literatur, observasi, dan wawancara yang berhubungan dengan ejaan bahasa Indonesia.

Hasil yang dicapai dalam penelitian ini adalah sebuah buku ejaan bahasa Indonesiadengan konsep sebagai berikut.

\section{Konsep Dasar Perancangan}

Layout Buku

Pada re-designbuku Pedoman Umum Ejaan Bahasa Indonesia, peneliti memfokuskan pada pola keterbacaan sebuah informasi, dimana hal ini lebih difokuskan pada komposisi layout yang digunakan. Peneliti mencoba menggunakan empat buah jenis layout yang masing-masing diletakkan sesuai dengan porsinya. Layout yang dimaksud antara lain adalah Copy Heavy Layout, Type Specimen Layout, Jumble Layout, dan Rebus Layout.
1. Copy Heavy Layout adalah jenis tata letak yang mengutamakan pada bentuk copy writing/naskah, dengan kata lain komposisinya layout-nya didominasi oleh penyajian teks (copy).

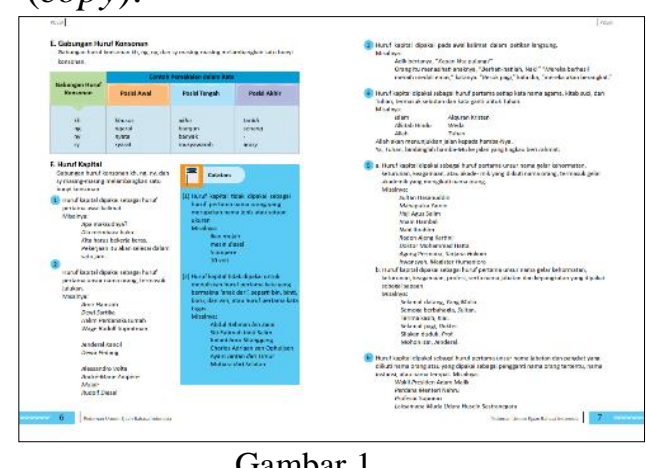

Gambar 1.

Konsep Layout

Sumber: Dokumen Pribadi

Jenis layout ini, peneliti lebih mengaplikasikan pada halaman isi buku yang konten materinya sudah mulai pada tahap memberi contoh penggunaan ejaan.

2. Type Specimen Layout adalah tata letak media informasi yang hanya menekankan pada penampilan jenis huruf dengan point size/ ukuran huruf yang besar. Pada umumnya hanya berupa headline saja.

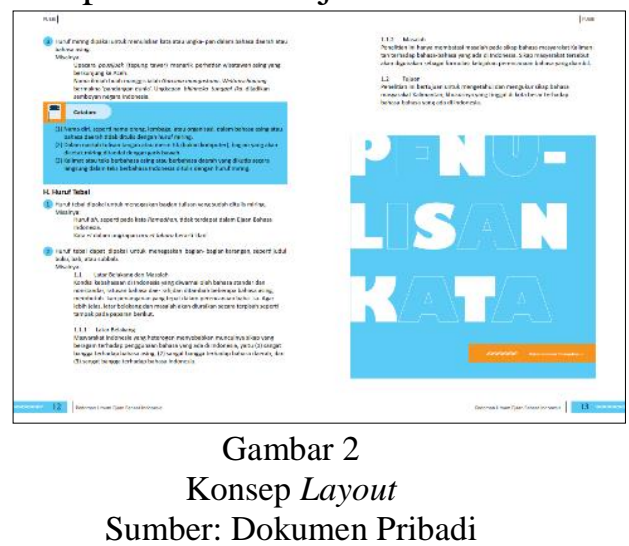

3. Jumble layout adalah penyajian media informasi dimana komposisi beberapa gambar dan teksnya disusun secara teratur. 


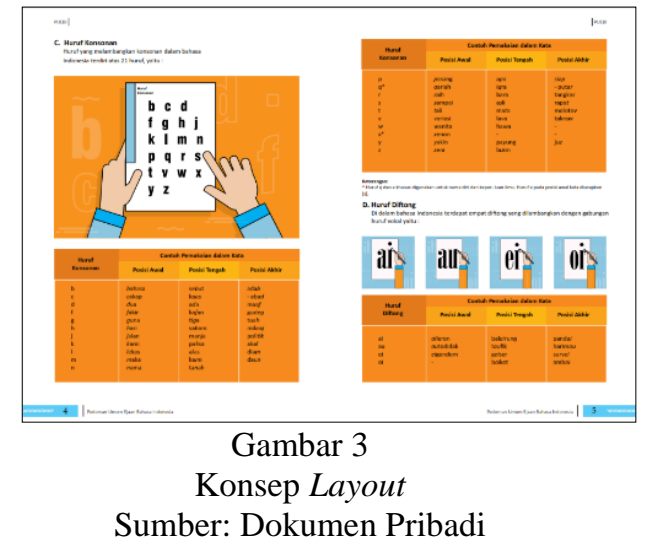

4. Rebus Layout adalah susunan tata letak media informasi yang menampilkan perpaduan gambar dan teks sehingga membentuk suatu cerita.

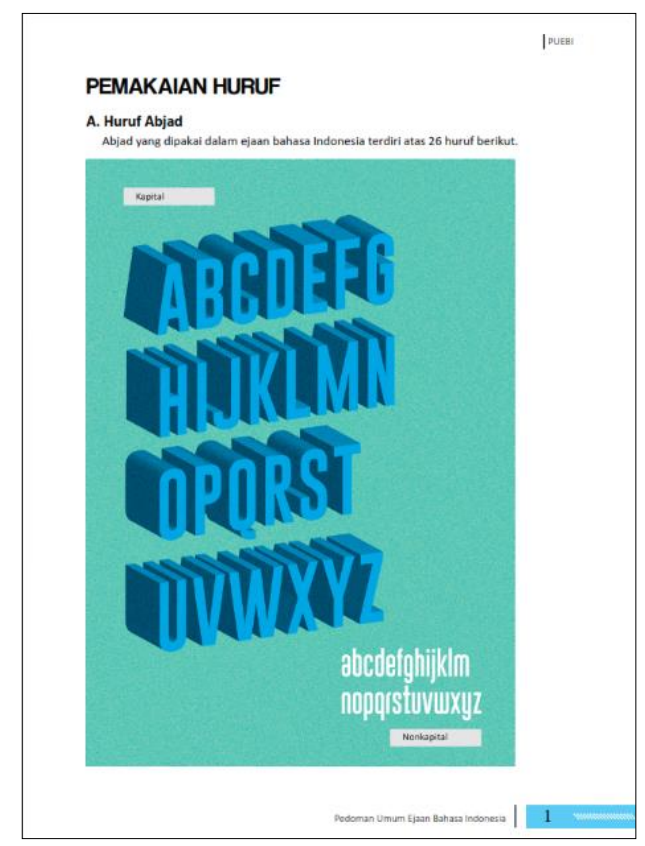

Gambar 4

Konsep Layout

Sumber: Dokumen Pribadi

Typography

Typography merupakan elemen desain yang juga memiliki peran dalam sebuah rancangan desain, terutama pada layout sebuah buku. Typography juga bisa dikatakan sebagai seni dalam menggunakan, memilih, dan mengaplikasikan huruf karena jika salah dalam memilih huruf, maka akibatnya adalah tidak sampainya informasi ketika media tadi dilihat/ dibaca. Bagian isi, peneliti menggunakan font Calibri Light yang masuk dalam kategori Sans Serif yang dikatakan sebagai huruf yang tidak memiliki kait. Jenis huruf ini lebih mudah dibaca karena secara bentuk memang dibuat lebih sederhana anatominya sehingga siapapun dapat dengan mudah membacanya.

ABCDEFGHIJKLMNOPQRSTUVWXYZ Abcdefghujklmnopqrstuvwxyz

$$
1234567890
$$$$
\text { :,"’<,>.?/_-+=!@\#\$\%^\&*()\{\}[] }
$$

Calibri Light

\section{ABCDEFGHIJKLMNOPQRSTUVW XYZ

$$
\begin{aligned}
& \text { Abcdefghujklmnopqrstuvwxyz } \\
& \text { 1234567890 } \\
& \begin{array}{c}
\text { :;"’>>.?/_-+=!@\#\$\%^\&*()\{\}[] } \\
\text { Calibri Bold }
\end{array}
\end{aligned}
$$

Gambar 5

Jenis Huruf

Sumber: Dokumen Pribadi

Prinsip dalam keilmuwan typography juga paneliti gunakan sebagai acuan dalam pemilihan hurufnya, yaitu :

1. Legibility

Legibility adalah kualitas pada huruf yang membuat huruf tersebut dapat terbaca dengan baik.

2. Readibility adalah penggunaan huruf dengan memperhatikan hubungannya dengan huruf lainnya sehingga dapat terlihat dengan jelas.

3. Visibility adalah kemampuan suatu huruf, kata, atau kalimat dalam suatu media visual.

4. Clarity adalah kemampuan hurufhuruf yang digunakan dalam suatu media, dapat dibaca dan dimengerti oleh target yang dituju. 
Ilustrasi
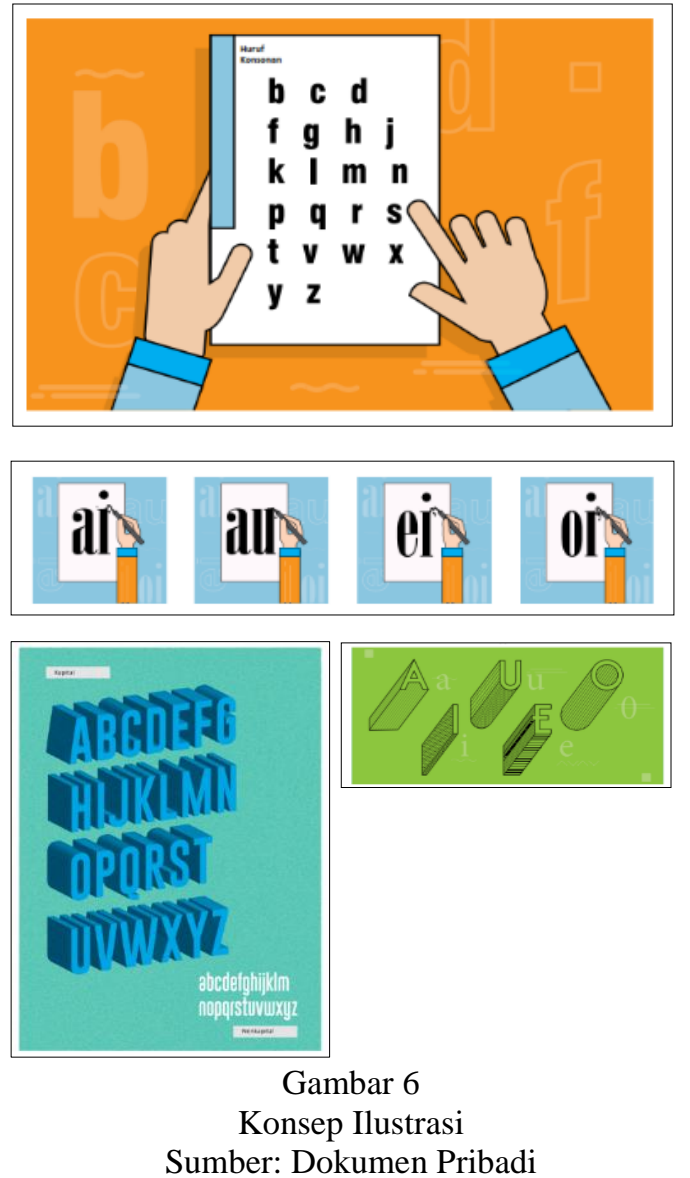

Ilustasi tidak harus selalu gambar yang mengambil peran dalam menunjang daya tarik media. Ilustrasi diartikan sebagai proses penggambaran objek, baik visual maupun audio dan lain-lain. Komunikasi visual merupakan suatu komunikasi melalui wujud yang dapat diserap oleh indera pengelihatan. Pada media komunikasi, khususnya media cetak, terdiri atas beberapa unsur yaitu warna, tipografi, ilustrasi, layout, fotografi, dan lain sebagainya. Untuk rancangan buku PUEBI ini, ilustrasi gambar digantikan dengan pengolahan huruf, sedangkan gambar ilustrasi hanya digunakan sebagai penunjang visual saja.

\section{Warna}

Dalam penggunaan warna, peneliti memilih warna-warna sekunder, dimana warna jenis ini adalah hasil perpaduan dari dua warna primer. Tidak hanya itu, dalam buku PUEBI ini juga peneliti menggunakan warna-warna pastel untuk memberikan kesan nyaman ketika dipandang mata. Berikut contoh warna-warna yang digunakan dalam buku PUEBI.

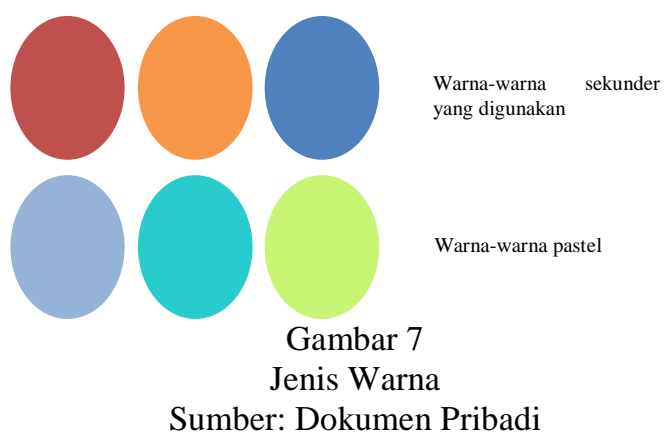

\section{PENUTUP}

Berdasarkan pembahasan di atas, dapat disimpulkan bahwa perancangan buku PUEBI ini didesain dengan menggunakan komposisi warna, ilustrasi, tipografi, dan layout sebagai berikut: Layout yang digunakan antara lain adalah Copy Heavy Layout, Type Specimen Layout, Jumble Layout, dan Rebus Layout.Bagian isi menggunakan font Calibri Light yang masuk dalam kategori Sans Serif yang dikatakan sebagai huruf yang tidak memiliki kait.Ilustrasi gambar digantikan dengan pengolahan huruf, sedangkan gambar ilustrasi hanya digunakan sebagai penunjang visual saja.Penggunaan warna menggunakan warna-warna pastel untuk memberikan kesan nyaman ketika dipandang mata.

Saran untuk penelitian/ perancangan selanjutnya adalah perlu adanya penggunaan media yang berbasis aplikasi dengan segmentasi mahasiswa sebagai bentuk keberlanjutan pembelajaran tentang ejaan Bahasa Indonesia. 


\section{DAFTAR PUSTAKA}

Ali, M. (2009). Pengembangan Media Pembelajaran Interaktif Mata Kuliah Medan Elektromagnetik. JurnalEdukasi@Elektro, 5(1), hlm. 11-18. Diambil dari http://journal.uny.ac.id

Alwi, H., Dardjowidjojo, S., Lapoliwa, H., Moeliono, A.M. (2014). Tata Bahasa Baku Bahasa Indonesia. Edisi Ketiga. Jakarta: Balai Pustaka.

Departemen Pendidikan Nasional. (2007). Kamus Besar Bahasa Indonesia. Edisi Ketiga. Jakarta: Balai Pustaka.

Depdiknas. (2003). Media Pembelajaran. Jakarta: Direktorat Pendidikan Dasar dan Menengah Direktoran Tenaga Kependidikan.

Hamalik, O. (2008). Kurikulum dan Pembelajaran. Jakarta: Sinar Grafika.

Handayaningrum, Y. (2010). Penerapan Media Cerita Bergambar (Cergam) untuk Meningkatkan Minat Baca Biologi Siswa pada Pokok Bahasan Bahan Kimia dalam Makanan Kelas VIII SMP Negeri 7 Surakarta Tahun Pelajaran 2008/2009. Skripsi. Program Studi Biologi, Fakultas Keguruan dan Ilmu Pendidikan, Universitas Sebelas Maret, Surakarta. Diambil dari http://digilib.uns.ac.id

KBBI Daring. (29 Agustus 2016). Pengertian Buku. Kbbi Kemdikbud.go.id.
Kusrianto, A. (2007). Pengantar Desain Komunikasi Visual. Yogyakarta: Andi.

Muhson, A. (2010). Pengembangan Media Pembelajaran Berbasis teknologi Informasi. Jurnal Pendidikan Akuntansi Indonesia, VIII(2), hlm. 1-10. Diambil dari http://staff.uny.ac.id

Pusat Bahasa Departemen Pendidikan Nasional Republik Indonesia. (2016). Kamus Besar Bahasa Indonesia (Daring). Diambil dari http://badanbahasa.kemdikbud.go .id

Rohani, A. (1997). Media InstructionalEducatif. Jakarta: Rineka Cipta.

Suyanto, E. (2011). Membina, Memelihara, dan Menggunakan Bahasa Indonesia Secara Benar. Yogyakarta: Ardana Media.

Tim Pengembang Pedoman Bahasa Indonesia. (2016). Pedoman Umum Ejaan Bahasa Indonesia. Jakarta: Badan Pengembangan dan Pembinaan Bahasa.

Triguno, B. (2013). Perancangan Buku Panduanpertolongan dan Keamanan dalam Arung Jeram. Jurnal Online Universitas Negeri Malang. Diambil dari http://jurnal.online.um.ac.id

Zaenal, A.E. dan Tasai, S.A. (2008). Cermat Berbahasa Indonesia untuk Perguruan Tinggi: Sebagai Mata Kuliah Pengembangan Kepribadian. Jakarta: Akapres. 